\title{
Aplicação de métodos multicritério ao problema de escolha de modelos de pagamento eletrônico por cartão de crédito
}

\author{
Carlos Francisco Simões Gomes ${ }^{\mathrm{a}}$, Helder Gomes Costa ${ }^{\mathrm{b} *}$ \\ ${ }^{a} \mathrm{cfsg} 1 @$ bol.com.br, UFF, Brasil \\ b*hgc@vm.uff.br, UFF, Brasil
}

\begin{abstract}
Resumo
É crescente o uso de meios de pagamentos eletrônicos no sistema econômico. Este trabalho realiza um estudo que compara os resultados da aplicação de diferentes métodos de apoio multicritério à decisão (AMD) à avaliação das três tecnologias de pagamento eletrônico mais comumente utilizadas no Brasil. Para isso utiliza-se um conjunto de métodos: THOR (S1, S2 e S3), ELECTRE (1 e 11) e PROMETHÉE 11. Os resultados da modelagem indicaram que não há uma prevalência significativa de uma alternativa, ou seja, uma tecnologia, sobre as outras. A adoção da abordagem multimétodos possibilitou uma análise de sensibilidade que fundamentou a escolha do decisor e possibilitou encontrar uma pequena vantagem de uma tecnologia. Entretanto, salientou ser essa vantagem mínima, o que ajuda a explicar a adoção dessas três tecnologias nos pagamentos eletrônicos.
\end{abstract}

Palavras-chave

Tecnologia. Multicritério. Pagamentos eletrônicos.

\section{Introdução}

A escolha de uma bandeira de cartão de crédito, para uso pessoal ou para uso institucional, insere-se em uma situação com as seguintes características:

- Trata-se de uma decisão do tipo discreta;

- 0 avaliador pode ou deve considerar mais de um aspecto ou critério no processo de escolha;

- Alguns critérios de avaliação são qualitativos, o que aumenta o grau de subjetividade da decisão.

0 apoio multicritério à decisão (AMD) é caracterizado pela modelagem de problemas decisórios discretos à luz de múltiplos de pontos de vista. Outra característica marcante do AMD é a sua propriedade de tratar problemas que envolvem critérios qualitativos ou avaliações subjetivas.

Observa-se então uma grande similaridade entre esse conjunto de características e aquelas inerentes à modelagem do problema de escolha de uma bandeira de cartão de crédito para uso pessoal ou institucional. Essa similaridade é um indicativo de que o AMD pode/deve ser aplicado na modelagem desse tipo de problema.

Por outro lado, há uma diversidade de métodos vinculados à disciplina AMD, tais como: AHP (SAATY, 1980, 1999), ANP (SAATY; VARGAS, 2006; SAATY; PENIWATI, 2008), TODIM (GOMES, 1989), THOR (GOMES, 1999; GOMES et al., 2008) e as famílias PROMETHÉE (BRANS; MARESCHAL; VINCKE 1984; BRANS; MARESCHAL, 1994; GOUMAS; LYGEROU, 2000; HU; CHEN, 2011) e ELECTRE (ROY, 1968, 1978; ROY; BERTIER, 1971; ROY; SKALKA, 1984; MOUSSEAU; SLOWINSKI; ZIELNIEWICZ, 1999; ROGERS; BRUEN; MAYSTRE, 2000).

A existência dessa diversidade de métodos de AMD motiva questões do tipo: há diferença entre os resultados quando diferentes métodos são aplicados ao problema da escolha do modo de pagamento eletrônico por cartão de crédito? Caso haja: quais são essas diferenças? A intensidade dessas perguntas é amplificada para o caso de métodos mais recentes 
que, portanto, demandam trabalhos de natureza comparativa multimétodos.

0 objetivo da pesquisa descrita neste artigo foi mapear as possíveis diferenças entre os resultados (ordenações geradas) da aplicação de diferentes métodos de AMD ao problema de escolha de modelos de pagamento eletrônico por cartão de crédito. Destaca-se que o objetivo do trabalho não é fazer uma comparação axiomática entre os métodos, mas apresentar ao decisor os resultados obtidos pela aplicação de diferentes métodos multicritério como forma de dar maior suporte a esse decisor no processo decisório.

Mais especificamente, comparam-se os estudos oriundos da aplicação do método THOR àqueles obtidos pelos métodos ELECTRE 1 e 11 e PROMETHÉE 11, tendo como pano de fundo a modelagem de um caso de escolha de uma bandeira de cartão de crédito para uso institucional, no qual foram consideradas três alternativas de tecnologia adotadas em processos de pagamento, especialmente aplicáveis em cartão de crédito e débito. A necessidade específica do caso decorre de ser uma decisão de investimento em que busca-se elicitar as preferências do decisor, bem como mostrar a ele que as ordenações oriundas dos métodos permitem verificar uma clara preferência entre as alternativas.

Este artigo está estruturado em quatro seções, além desta introdução: a seção 2 apresenta uma sintese das características e conceitos referentes ao AMD; na seção 3 descrevem-se os procedimentos metodológicos e o caso de aplicação; e a seção 4 apresenta as conclusões.

\section{Sobre os métodos de AMD}

Para Belton e Stewart (2004), o AMD busca pesquisar um número de alternativas, sob múltiplos critérios e objetivos em conflito, buscando gerar soluções compromisso e uma hierarquização das alternativas, de acordo com o grau de atração delas para o tomador de decisão.

Segundo Bouyssou (1986), uma abordagem multicritério apresenta as seguintes vantagens:

- Torna viável a construção de uma base para o diálogo entre analistas e decisores, que fazem uso de diversos pontos de vista comuns;

- Provê facilidade na incorporação das incertezas dos dados sobre cada ponto de vista;

- Permite entender cada alternativa como um compromisso entre objetivos em conflito. Esse argumento destaca o fato de que uma situação em que uma alternativa é superior às restantes, sobre todos os pontos de vista, raramente será encontrada.
Conforme descrito em textos como o de Roy e Boyssou (1993) e no de Gomes e Gomes (2012), no contexto do apoio à decisão, o resultado pretendido em determinado problema pode ser identificado entre quatro tipos de problemática de referência, descritas a seguir:

a) Problemática P. $\alpha$ - tem como objetivo esclarecer a decisão pela escolha de um subconjunto de alternativas tão restrito quanto possível, tendo em consideração a escolha final de uma única ação. Esse conjunto conterá as "melhores ações" ou as ações "satisfatórias". 0 resultado pretendido é, portanto, uma escolha;

b) Problemática P. $\beta$ - tem como objetivo esclarecer a decisão por uma triagem resultante da alocação de cada alternativa a uma categoria (ou classe). As diferentes categorias são definidas a priori, com base em normas aplicáveis ao conjunto de ações. 0 resultado pretendido é, portanto um procedimento de classificação;

c) Problemática P. $\gamma$ - tem como objetivo esclarecer a decisão por um arranjo obtido pelo reagrupamento de todas ou parte (as alternativas mais satisfatórias) das ações em classes de equivalência. Essas classes são ordenadas de modo completo ou parcial, conforme as preferências do(s) decisor(es). 0 resultado pretendido é um procedimento de ordenação;

d) Problemática P. $\delta$ - tem como objetivo esclarecer a decisão por uma descrição, em linguagem apropriada, das ações e de suas consequências. 0 resultado pretendido é, portanto, uma descrição ou um procedimento cognitivo.

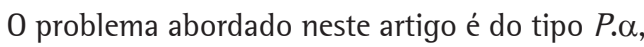
pois trata-se de um problema de escolha de uma opção dentre um conjunto finito e discreto de alternativas.

\section{Procedimentos metodológicos}

Segundo reportado em Descartes (1637), ao se relatar uma pesquisa é necessário o detalhamento dos passos efetuados na mesma, objetivando a sua reprodução. Para Creswell (2011), essa necessidade ocorre tanto em pesquisas qualitativas quanto em quantitativas. Adotando essa orientação, descrevem-se a seguir as etapas da modelagem efetuada, descrevendo-se a aplicação dos diferentes métodos multicritério ao problema de seleção do cartão de crédito.

0 desenvolvimento desta pesquisa está estruturado nas seguintes etapas:

1. Contextualização do problema;

2. Definição das alternativas viáveis;

3. Definição do conjunto de critérios;

4. Avaliação das alternativas;

5. Escolha e aplicação dos algoritmos de ordenação;

6. Intercomparação dos resultados. 


\subsection{Contextualização do problema}

Desde a estabilidade econômica no Brasil, a qual surgiu após a criação do Plano Real, no ano de 1994, estudos têm demonstrado uma explosão na forma como o brasileiro usa a ferramenta cartão de crédito e débito. Segundo dados da ABECS (ASSOCIAÇÃO..., 2012) o valor anual das transações em cartão de crédito, que era de $R \$ 5,7$ bilhões, em 1994, cresceu para $\mathrm{R} \$ 309,3$ bilhões, em 2010. As Figuras 1, 2 e 3, obtidas de ABECS (ASSOCIAÇÃO..., 2012), mostram o

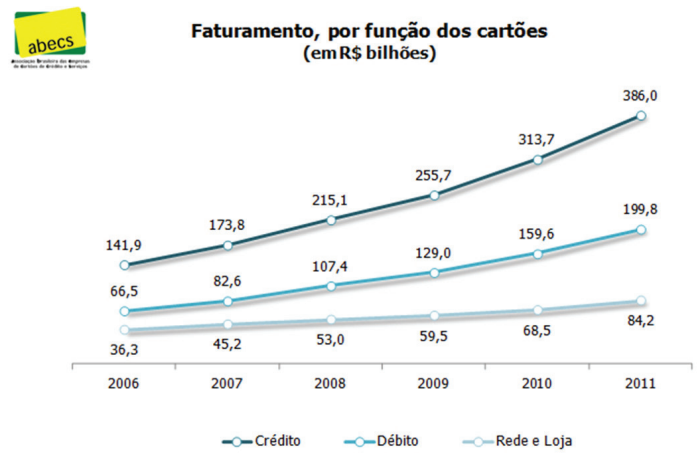

Figura 1. Faturamento em cartões. Fonte: ABECS (ASSOCIAÇÃO..., 2012).

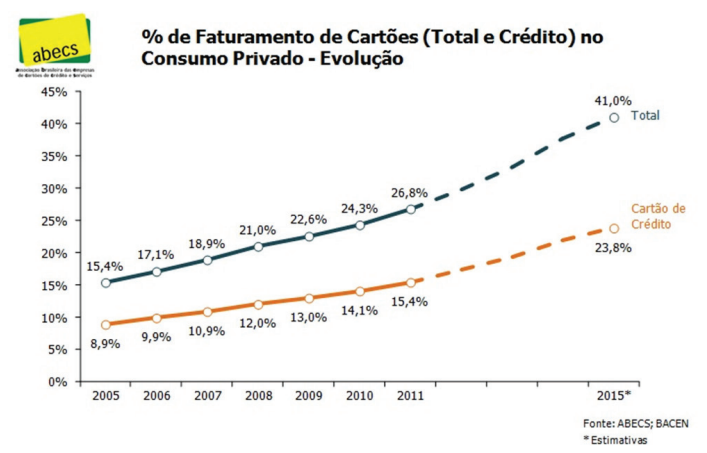

Figura 2. Faturamento dos cartões pelo setor privado. crescimento do uso do cartão de crédito em número de cartões e em faturamento.

De Oliveira, lkeda e Santos (2004) observam que o uso de cartão de crédito está se expandindo em diversos segmentos da população, consequentemente, ocasionando mudanças no comportamento de grupos que não tinham acesso a esse serviço. Examinando os dados de 2006 a 2011, constantes nas Figuras 1, 2 e 3 , nota-se uma forte expansão no uso de pagamento eletrônico. Essa expansão, em parte, se deve a uma maior estabilidade econômica atingida pelo Brasil, em especial nas últimas décadas.

Alves e Menezes (2007) destacam que outro fator a ser considerado é o conforto e a maior segurança proporcionada pelo uso de soluções eletrônicas de pagamento. Essa afirmação é corroborada pela ABECS (ASSOCIAÇÃO..., 2012), segundo a qual o pagamento eletrônico atende ao desejo do vendedor de saber com antecedência se uma pessoa (física ou jurídica) está autorizada ou possui crédito suficiente para honrar uma compra. Diferentemente do cheque, as transações eletrônicas, em geral, só são liberadas após a aprovação de um emissor (garantidor) da operação.

0 conceito cartão de crédito é o mais comum e difundido meio de pagamento eletrônico, seu funcionamento é relativamente simples para o consumidor final, porém requer um grau de investimento e sofisticação elevado por parte das instituições que operam o sistema.

\subsubsection{Pagamentos por cartão de crédito no Brasil}

Conforme reportado por Gomes e Costa (2011), no Brasil, o primeiro cartão de crédito surgiu no ano de 1956, pelas mãos do empresário tcheco Hanus

\begin{tabular}{|c|l|r|r|r|}
\hline \multicolumn{5}{|c|}{ Resumo de indicadores - 2010/2011 (Dezembro) } \\
\cline { 2 - 6 } \multicolumn{1}{l|}{ abeCS } \\
\cline { 2 - 6 }
\end{tabular}

Figura 3. Comparação dos indicadores dezembro 2010 com dezembro 2011. Fonte: ABECS (ASSOCIAÇÃO..., 2012). 
Tauber, que comprou uma franquia do Diners Club, inicialmente aceito apenas por um seleto grupo de restaurantes e que era apenas um cartão de compras (requeria o pagamento integral da fatura). Posteriormente, ele passou a oferecer a função crédito. Em 1968, o Bradesco lançou o Elo, o primeiro cartão de crédito brasileiro, que funcionava na rede do BankAmericard, posteriormente chamada Visa. 0 Brasil, mesmo possuindo um dos melhores sistemas de compensação bancária do mundo, a partir de 2000 passa a verificar a gradual a diminuição no uso de cheques, o que corroborou ainda mais para o aumento da importância do uso de cartões de crédito. Ainda com base nos dados das Figuras 1, 2 e 3 da ABECS (ASSOCIAÇÃO..., 2012), nota-se que há um crescimento em número de transações, quantidade de cartões e valor total das transações. Segundo a ABECS (ASSOCIAÇÃO..., 2012), os brasileiros estão cada vez mais preferindo os meios eletrônicos para pagar as despesas.

Conforme descrito em Gonzaga (2010), o modelo de operação adotado no Brasil é conhecido como esquema de quatro pontas, modelo no qual os bancos emissor e credenciador são entidades distintas. A Figura 4 representa as relações entre os agentes envolvidos, os quais são descritos a seguir:

- Bancos emissores: Instituição, geralmente bancária, que emite o cartão e efetua a cobrança e o recebimento dos recursos do portador, responsabilizando-se pela quitação dos débitos por ele contraídos na rede credenciada;

- Credenciadores ou adquirentes: Agente encarregado do credenciamento de estabelecimentos comerciais, da instalação e da manutenção dos terminais para captura e transmissão dos dados das transações eletrônicas;

- Vendedor: Pessoa jurídica fornecedora de bens ou serviços habilitada pelo credenciador para receber pagamentos com cartão de crédito, dispondo, para tal, dos equipamentos necessários à captura eletrônica e à transmissão das informações;

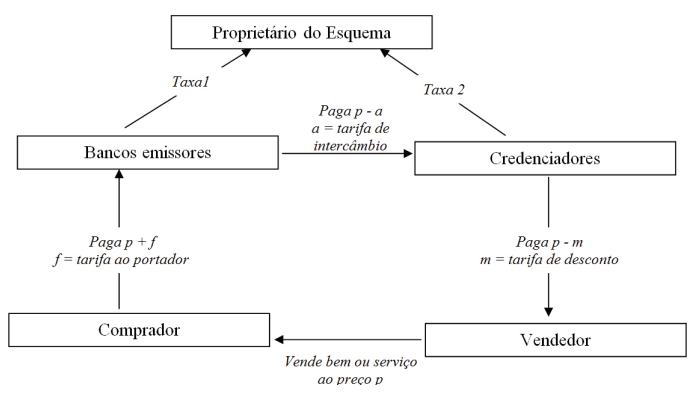

Figura 4. Esquema de mercado de cartões quatro pontas (GONZAGA, 2010).
- Comprador: Pessoa física ou jurídica devidamente autorizada pelo emissor para portar o cartão;

- Administradora: Detentora de todos os direitos e deveres da utilização da marca, podendo, também, exercer as funções do emissor;

- Sistema de liquidação: Sistema no qual as transações com cartão de crédito envolvendo transferências interbancárias são liquidadas.

\subsubsection{Tecnologia}

Desde a criação dos primeiro cartões de pagamento, as empresas têm buscado novas tecnologias, com o propósito de trazer conforto e maior segurança para as transações por elas acolhidas. 0 que no início era um cartão de papel evoluiu para versões magnéticas, passando por cartões com chip e atualmente já é possivel encontrar sistemas de pagamento totalmente sem fio.

A ABECS (ASSOCIAÇÃO..., 2012) considera que um cartão magnético é um cartão de plástico com uma trilha magnética que contém as informações do usuário. Atualmente, a tecnologia de cartões magnéticos já é considerada obsoleta, pois é relativamente fácil adquirir e fazer uso de máquinas capazes de copiar os cartões. Como medidas adicionais de segurança, a maior parte dos cartões possuía a gravação do nome do dono em autorrelevo além de possuir um código de verificação impresso na parte de trás do cartão. Todas essas medidas visavam reprimir fraudes e uso indevido.

Segundo Guimarães Neto (1992) e Pessoa (1992), a ocorrência de um número significativo de fraudes com cartões magnéticos convencionais induziu os bancos emissores a substituírem sua base de cartões por cartões com chip embarcado (os SmartCards), os quais são cartões dotados de memória e microprocessador capaz de tomar decisões, armazenar diversas informações e suportar aplicações com diversas funções. Para Albertin e Albertin (2009), a incorporação dessa tecnologia objetivou dar maior segurança à transação, visto que esse tipo de tecnologia, além de requerer senha pessoal para as transações, é mais difícil de ser clonada. Apesar dessa evolução, conforme reportado pela ABECS (ASSOCIAÇÃO..., 2012), nesse ano, a maioria dos cartões no Brasil ainda usava tecnologia do cartão magnético.

Este estudo atende uma empresa (pessoa jurídica) que, buscando aumentar as possibilidades de recebimento de pagamento dos clientes - sendo que uma dessas formas seria o cartão de crédito -, buscou identificar qual a melhor alternativa de cartão de crédito deveria ser implementada. A empresa já operava com débito automático. 0 decisor foi o dono da empresa (microempresa). 


\subsection{Definição e descrição das alternativas}

Atualmente há no mercado brasileiro de cartões de crédito e débito três tipos de cartão: Cartão de Crédito Bandeirado; Cartão Private Label; e Cartão Co-Branded ou Híbrido. Esses tipos de cartão constituem as alternativas apresentadas ao decisor.

\subsubsection{Cartão de Crédito Bandeirado}

0 Cartão de Crédito Bandeirado é o mais comum no mercado brasileiro. Conforme Saab e Tavares (2002) e Melo (2006), é geralmente emitido por um banco e acolhido por uma bandeira. Toda conta de cartão de crédito possui um limite de compras definido pelo banco emissor, e as compras efetuadas reduzem o limite disponível até que, quando esse é insuficiente, novas compras são negadas. 0 titular recebe mensalmente uma fatura e o seu pagamento libera o limite para ser usado novamente. 0 mercado já está saturado e requer grandes investimentos em marketing e possiveis novos diferenciais para o cliente, o que atua como barreira de entrada a novos lançamentos desse tipo de cartão. Essa situação também induz à adoção de programas de fidelização por parte dos bancos que tradicionalmente oferecem esse tipo de cartão.

\subsubsection{Cartão Private Label}

Também segundo Saab e Tavares (2002) e Melo (2006), Cartões Private Label são emitidos por um varejista e usualmente são válidos apenas para a realização de compras com esse varejista ou em rede credenciada. São diferentes dos cartões de crédito de uso genérico pois sua bandeira de não têm aceitação em uma rede ampla de vendedores ou prestadores de serviço. Por terem uma aceitação limitada a uma única cadeia de varejistas, são cartões direcionados a um público específico e que, na maioria das vezes, já é cliente desse varejista. Seu surgimento no Brasil remonta à década de 1970, com os extintos cartões Mappin e Mesbla, precursores do conceito no Brasil. Esse tipo de cartão possibilita que pequenos varejistas ofereçam a seus clientes um sistema prático de pagamento que ainda gera uma maior fidelização e garante que $100 \%$ do limite do cartão será usado para compras no estabelecimento do lojista ou de parceiro. Por outro lado, transfere alguns riscos e custos da operação para o varejista.

\subsubsection{Cartão co-branded ou híbrido}

Ainda como reportado em Melo (2006), os Cartões Co-Branded são cartões de crédito similares aos Cartões Private Label, só que com a vantagem de o cliente poder comprar em qualquer estabelecimento credenciado na bandeira do cartão e não somente na rede varejista em que ele foi emitido. Possui as características de um cartão de crédito bandeirado, porém quando usado no estabelecimento do varejista parceiro passa a funcionar como um Cartão Private Label, reduzindo o custo da transação. Diferentemente dos cartões de crédito bandeirados, esses não possuem tantas vantagens, como programas de fidelização e milhagens.

\subsection{Definição do conjunto de critérios}

Com base em estudo da literatura, especialmente os trabalhos de Aksu, Pektaş e Eseoğlu (2011), Aydin et al. (2009), Worthington, Russell-Bennett e Härtel (2010), Gonzaga (2010), Guimarães Neto (1992), Saab e Tavares (2002), Melo (2006), De Oliveira, lkeda e Santos (2004) e Coelho, Raittz e Trezub (2006), e em posterior entrevista com os envolvidos no processo decisório, o que incluiu os decisores e os especialistas, foram elencados 14 critérios para avaliação dos tipos de cartão de crédito. Segue a descrição desses critérios:

A. Aplicações adicionais: Possibilidade de facilitar formas diferentes de uso para o cartão que não somente a função crédito, como saque, pagamento de contas, seguros etc;

B. Custo de implantação: Custo de implantação do sistema de captura e pagamento no estabelecimento lojista;

C. Custo para o cliente: Custo total para o cliente que possui o cartão, como taxas, anuidades, tarifas etc. (excluindo o custo anterior);

D. Custo por transação (varejista): Custo para o varejista que possui o sistema, como tarifas, taxas, anuidades, aluguéis de aparelhos etc;

E. Facilidade de difusão: Facilidade que o produto tem de se difundir entre o público alvo escolhido;

F. Fidelização do varejista: Potencial de fidelização que o produto possui perante o varejista;

G. Fidelização do cliente: Potencial de fidelização que o produto tem junto ao cliente, intimamente ligado com os custos e aplicações disponiveis;

H. Necessidade de investimentos no futuro: Necessidade de investimentos para adequar as vendas dos atuais produtos e mantê-los de acordo com as tecnologias disponíveis no mercado;

1. Número de locais que atende: Quantidade de estabelecimentos que podem ser atendidos por cada tipo de modelo;

J. Potencial de crescimento: Facilidade de expansão da atual rede e base de clientes; 
K. Risco para o cliente: Potencial de risco para o cliente, decorrente de problemas como fraudes, erros etc;

L. Risco para o varejista: Potencial de risco para o varejista, decorrente de problemas como fraudes, erros etc;

M. Usabilidade para o cliente: Grau de facilidade de uso do sistema do ponto de vista do cliente;

N. Usabilidade para o varejista: Grau de facilidade de uso do sistema do ponto de vista do varejista.

É importante registrar que todas as avaliações feitas pelos decisores foram efetuadas em um contexto de consenso. Isso implica que todas as avaliações devem ser consideradas como de uma única estação de decisão.

\subsection{Atribuições de pesos e avaliação das alternativas}

A Figura 5 apresenta uma matriz com a avaliação das três alternativas à luz do conjunto de critérios. Essas avaliações e as atribuições de peso aos critérios foram suportadas por entrevistas com os diretores da empresa e com especialistas no tema do estudo. As avaliações consideraram uma escala verbal com cardinalidade cinco (baixo, médio-baixo, médio, médio-alto e alto). 0 uso de escala verbal para esta avaliação deveu-se a:

- Dificuldade de encontrarem-se valores numéricos para quantificar as alternativas em cada critério;

- Segurança das informações.

Os critérios associados a custo, tais como custo de implantação, custo para o cliente, custo por transação, bem como número de locais que atende seriam critérios mensuráveis; entretanto a empresa possuía estimativas, baseadas em benchmarking. Os decisores preferiram fazer uma comparação verbal, considerando os valores, e colocar posteriormente de forma proporcional os valores na escala com valores lineares.

A passagem da escala verbal para a escala linear obedeceu ao princípio de $\mathrm{y}=\mathrm{ax}+\mathrm{b}$; em que $\mathrm{a}$ atratividade da diferença da pontuação, o número 1 no exemplo de 5 para 4 , ou seja, 5 - 4=1, representa a mesma atratividade de uma mudança de pontuação de $3-2=1$.

Houve também necessidade de proteger esses valores por questões de segurança empresarial. A Figura 6 ilustra os pesos atribuídos aos critérios e as avaliações atribuídas aos cartões, que levou em conta a transformação da escala verbal da Figura 5 em uma escala numérica de intervalos.

A atribuição de peso para os critérios foi efetuada conforme os passos:

- Passo 1: Pesquisa feita em informações obtidas em recentes estudos do Banco Central do Brasil sobre o Diagnóstico do Sistema de Pagamentos Brasileiro;

- Passo 2: Consulta aos profissionais do mercado;

- Passo 3: Envio de relatório para consideração pelos decisores.

Ao final desses passos, validou-se a seguinte estrutura de preferências do decisor, para os critérios: $\mathrm{B}>\mathrm{D}=\mathrm{H}>\mathrm{F}=\mathrm{I}>\mathrm{J}>\mathrm{N}=\mathrm{O}>\mathrm{C}=\mathrm{G}>\mathrm{E}>\mathrm{A}$ $>\mathrm{L}=\mathrm{M}$. A partir dessa sequência e com base nas orientações para atribuição de peso encontradas no método Swing Weighting (EDWARDS, 1977)

\begin{tabular}{|c|c|c|c|c|}
\hline & Características: & $\begin{array}{c}\text { Cartão } \\
\text { Co-Branded } \\
\text { ou Híbrido }\end{array}$ & $\begin{array}{c}\text { Cartão } \\
\text { Private Label }\end{array}$ & $\begin{array}{c}\text { Cartão de } \\
\text { crédito } \\
\text { bandeirado }\end{array}$ \\
\hline A & Aplicações adicionais & Médio & Médio-Baixo & A/to \\
\hline $\mathrm{B}$ & Custo de Implantação & Alto & Médio & Médio-Baixo \\
\hline $\mathrm{C}$ & Custo para o cliente & Médio & Baixo & Alto \\
\hline $\mathrm{D}$ & Custo por Transação (Varejista) & Médio & Médio-Baixo & Alto \\
\hline $\mathrm{E}$ & Facilidade de difusão & Médio-Alto & A/to & Médio \\
\hline $\mathrm{F}$ & Fidelização ao Varejista & Médio & Alto & Baixo \\
\hline G & Fidelização do Cliente & Alto & Médio & Médio-Alto \\
\hline $\mathrm{H}$ & Necessidade de investimentos no futuro & Médio & Médio-Alto & Médio-Baixo \\
\hline 1 & № de locais que atende: & Alto & Baixo & Alto \\
\hline $\mathrm{J}$ & Potencial de crescimento: & Alto & Médio-Alto & Médio \\
\hline $\mathrm{L}$ & Risco para o Cliente & Médio-Baixo & Baixo & Médio-Baixo \\
\hline$M$ & Risco para o Varejista & Baixo & Baixo & Médio \\
\hline $\mathrm{N}$ & Usabilidade ao Cliente & Médio-Alto & Médio-Baixo & Alto \\
\hline $\mathrm{O}$ & Usabilidade ao Varejista & Alto & Médio & Alto \\
\hline
\end{tabular}

Figura 5. Avaliações atribuídas às alternativas. 


\begin{tabular}{|c|c|l|c|c|c|}
\hline & Peso & \multicolumn{1}{|c|}{ Características: } & $\begin{array}{c}\text { Cartão } \\
\text { Co-Branded } \\
\text { ou Híbrido }\end{array}$ & $\begin{array}{c}\text { Cartão } \\
\text { Private Label }\end{array}$ & $\begin{array}{c}\text { Cartão de } \\
\text { crédito } \\
\text { bandeirado }\end{array}$ \\
\hline \hline B & 100 & Custo de Implantação & 5 & 3 & 2 \\
\hline D & 95 & Custo por Transação (Varejista) & 3 & 2 & 5 \\
\hline H & 95 & Necessidade de investimentos no futuro & 3 & 4 & 2 \\
\hline F & 90 & Fidelização ao Varejista & 3 & 5 & 1 \\
\hline I & 90 & No de locais que atende: & 5 & 1 & 5 \\
\hline J & 85 & Potencial de crescimento: & 5 & 4 & 3 \\
\hline N & 80 & Usabilidade ao Cliente & 4 & 2 & 5 \\
\hline O & 80 & Usabilidade ao Varejista & 5 & 3 & 5 \\
\hline C & 75 & Custo para o cliente & 3 & 1 & 5 \\
\hline G & 75 & Fidelização do Cliente & 5 & 3 & 4 \\
\hline E & 70 & Facilidade de difusão & 4 & 5 & 3 \\
\hline A & 65 & Aplicaçães adicionais & 3 & 2 & 5 \\
\hline L & 60 & Risco para o Cliente & 2 & 1 & 2 \\
\hline M & 60 & Risco para o Varejista & & 1 & 3 \\
\hline
\end{tabular}

Figura 6. Peso dos critérios e classificação das alternativas em cada critério.

obteve-se o peso de cada critério. Observa-se que não foi utilizado o método, mas sim o princípio do swing weights para ajudar o decisor a atribuir pesos para os critérios. 0 critério Custo de mplantação foi considerado o mais relevante, por isso recebeu peso 100, seguido pelos critérios Custo por transação e Necessidade de investimentos no futuro, ambos com peso 95 (Figura 6). A referência feita pelos autores do presente trabalho ao uso do princípio do Swing Weighting, deve-se ao fato de que após o estabelecimento do critério mais importante, pelo decisor, e atribuído a ele o peso 100, o decisor foi convidado a atribuir a cada critério menos importante o quanto esse era menos importante que o critério principal. Portanto, essa referência é ao conceito e não ao uso do método do Swing Weighting de forma integral. É importante registrar que o decisor declarou-se confiante ao utilizar essa estratégia de obtenção dos pesos.

\subsection{Aplicação dos algoritmos de ordenação}

Conforme descrito na introdução, este trabalho estabelece uma inédita comparação entre a modelagem e métodos de AMD. Esse tipo de comparação só é viável para métodos AMD de uma mesma escola (que tenham os mesmo princípios). Vincke (1989) classifica as abordagens de AMD como:

- A abordagem do critério único de síntese, que constrói uma função de agregação única e que tem sido classificada como pertencente à Escola Americana. Segundo Costa et al. (2007), dentre os métodos e teorias que se baseiam nessa abordagem, destacam-se o AHP e a teoria da utilidade multiatributo (MultiAttribute Utility Theory, MAUT), delineada em Fishburn $(1966,1968,1970)$ e consolidada em Keeney e Raiffa (1976). A essa lista podem ser agregados os métodos TODIM e ANP;

- Antunes et al. (1989) relatam que as abordagens interativas alternam fases de cálculo com fases de decisão, com o analista de decisão interagindo com o modelo. Para Costa et al. (2007, p. 233), “[...] esse tipo de abordagem é especialmente importante em situações em que se esteja buscando uma única solução que seja ótima ou que esteja próxima do ponto ótimo";

- Costa et al. (2007, p. 233) consideram que, “[...] no âmbito dos métodos de subordinação, um conjunto finito de alternativas/ações (A) são valoradas sobre uma família/vetor de critérios (F), construindo-se relações de subordinação não compensatórias entre as alternativas". Entre os métodos da Escola Francesa, destacam-se os métodos ELECTRE e PROMETHÉE, sendo que pode-se incluir o método THOR, desenvolvido no Brasil, como um dos métodos da Escola Francesa. Costa et al. (2007) apresentam uma ilustração didática do conceito de subordinação ou de sobreclassificação.

Para estabelecer bem a diferença entre o emprego da média ponderada e dos métodos de superação, pode-se fazer uma analogia com o que acontece em uma partida de voleibol no confronto entre os times A e B. Se no primeiro set $B$ ganha de A por 25 a zero, porém nos demais três sets $A$ ganha de $B$ por 25 a 20, duas análises são feitas:

1. Usar-se a média ponderada para obter o resultado final. Nesse caso B seria o vencedor da partida por 85 a 75 ;

2. Usar-se o número de sets para definir o vencedor. Neste caso, A seria o vencedor por 3 a 1;

3. 0 princípio fundamental dos métodos de superação pode ser considerado semelhante a essa segunda 
abordagem, se considerarmos que cada set equivale a cada um dos critérios da análise multicritério.

A comparação de resultados entre métodos é viável com métodos de uma mesma escola ou princípio de agregação. Considerando que o THOR é um método que incorpora aspectos da Escola Francesa, assim como os métodos ELECTRE e PROMETHÉE, optou-se por comparar os resultados obtidos pelo THOR com os oriundos da aplicação dos métodos ELECTRE 1 e 11 e PROMETHÉE 11. A seguir descreve-se a aplicação dos métodos THOR, ELECTRE 1 e 11 e PROMETHÉE 11 ao problema de escolha do modelo de cartão de crédito para pagamento eletrônico.

\subsubsection{Aplicação do THOR}

0 THOR foi proposto por Gomes (1999) e é baseado na modelagem de preferência (o que o aproxima da Escola Francesa) e nas teorias multiatributo e da utilidade (o que o aproxima da Escola Americana). 0 uso dessas teorias permite que a atratividade de uma alternativa seja quantificada pela criação de uma função de agregação não transitiva. A implementação computacional do THOR pode ser considerada como um sistema de apoio à decisão (SAD) devido ao software apresentar um banco de modelos que possui três algoritmos para ordenação, bem como usar a teoria dos conjuntos aproximativos (Rough Set) como datamining, possuir um banco de dados, denominado Firebird e uma interface de comunicação construída na linguagem Delphi7. 0 Thor se aproxima da Escola Americana pelo fato de fazer uma função agregadora de transitividade, considerando o peso dos critérios, em que uma alternativa supera a outra. 0 THOR também se aproxima da Escola Francesa por utilizar a modelagem de preferências e considerar limites de preferência denominados p e q quando compara as alternativas dentro dos critérios. Conforme reportado por Gomes (2005), à luz do estado da arte no apoio multicritério à decisão (AMD), o THOR fez as seguintes contribuições:

- Apresenta algoritmo híbrido que agrega simultaneamente conceitos da teoria dos conjuntos aproximativos (TCA), teoria dos conjuntos nebulosos, teoria da utilidade e modelagem de preferências;

- Ordena alternativas discretas em processos decisórios transitivos ou não;

- Faz a eliminação de critérios redundantes, considerando simultaneamente se a informação é dúbia (uso da TCA) e se ocorre elevação da imprecisão do processo de decisão (uso da teoria dos conjuntos nebulosos);

- Quantifica a imprecisão e a utiliza no processo de decisão AMD;
- Permite simultaneamente a entrada de dados de mais de um decisor, possibilitando que eles expressem seu(s) juízo(s) de valor(es) em escala de razões, intervalos ou ordinal;

- A nova fórmula utilizada pelo THOR (para atribuição de pesos na escala ordinal) foi obtida após o estudo das três fórmulas existentes na literatura;

- 0 decisor também pode executar o processo de decisão sem atribuir pesos aos critérios;

- Elimina a necessidade de alguns algoritmos que se baseiam na modelagem de preferências de determinar um valor, normalmente arbitrário, para a concordância.

Cardoso et al. (2009) e Gomes et al. (2008) destacam que devido à capacidade limitada da mente humana para comparar simultaneamente vários aspectos de um problema, o THOR é utilizado como ferramenta para apoiar a comparação das alternativas, as quais são classificadas nos diferentes critérios. Baseado em uma comparação paritária, o princípio de julgamentos comparativos é aplicado para determinar a importância relativa dos critérios.

Gomes e Gomes (2012) afirmam que o SAD Thor permite a entrada de dados de mais de um decisor simultaneamente, possibilitando que eles expressem seu(s) juízo(s) de valor(es) em escala de razões, escala de intervalos ou escala ordinal.

Algumas informações adicionais são necessárias para a aplicação da metodologia:

- Estabelecimento de um peso para cada critério, representando a importância relativa entre eles - embora exista a possibilidade de trabalhar sem pesos, essa é utilizada quando os decisores são incapazes de atribuir pesos aos critérios;

- Estabelecimento de um limiar de preferência $\left(p_{j}\right)$ e de indiferença $\left(q_{j}\right)$ para cada critério j;

- Estabelecimento da discordância.

0 limite de indiferença, $q_{j}\left[g_{j}(a)\right]$, explicita um limiar superior de indiferença. Ou seja: para valores de $\left[g_{j}(b)-g_{j}(a)\right]$ inferiores ao valor de $q_{j}\left[g_{j}(a)\right]$, o decisor considera a alternativa $a$ indiscernível à $b$, à luz do critério j. 0 limite de preferência, $p_{j}\left[g_{j}(a)\right]$, representa um limiar inferior de preferência de tal forma que deve haver uma diferença $\left[g_{j}(b)-g(a)\right]$ superior ao valor de $p_{j}\left[g_{j}(a)\right]$ para que se aceite que há uma preferência estrita da alternativa $b$ sobre a $a$.

Para Gomes et al. (2009), o estabelecimento de uma discordância para cada critério reside no fato de que não existem critérios em que a intensidade de preferência de $b$ em relação a $a$ ultrapasse um limite aceitável.

A quantificação da imprecisão para cada peso e para cada classificação das alternativas deve ocorrer, uma vez que o julgamento de valor empregado nos 
métodos de apoio multicritério à decisão nem sempre pode ser expresso de maneira segura e precisa.

Ressalta-se que as relações de sobreclassificação possuem um quantitativo numérico que representam o valor da alternativa, através de uma função de valor aditiva (ALENCAR; COSTA; GOMES, 2005). Essa aproximação permite representar a relação de sobreclassificação e a hierarquia dos valores das alternativas. Para que uma alternativa seja melhor do que a outra, três situações devem ser admitidas (GOMES, 1999):

$$
\begin{aligned}
& S 1: \sum_{j=1}^{n}\left(w_{j} \mid a P_{j} b\right)>\sum_{j=1}^{n}\left(w_{j} \mid a Q_{j} b+a I_{j} b+a R_{j} b+b Q_{j} a+b P_{j} a\right) \\
& S 2: \sum_{j=1}^{n}\left(w_{j} \mid a P_{j} b+a Q_{j} b\right)>\sum_{j=1}^{n}\left(w_{j} \mid a I_{j} b+a R_{j} b+b Q_{j} a+b P_{j} a\right) \\
& S 3: \sum_{j=1}^{n}\left(w_{j} \mid a P_{j} b+a Q_{j} b+a I_{j} b\right)>\sum_{j=1}^{n}\left(w_{j} \mid a R_{j} b+b Q_{j} a+b P_{j} a\right)
\end{aligned}
$$

$R$ é a não comparabilidade e $w_{j}$ representa o peso do critério $j$; e os critérios são $j=1,2, \ldots, n$, onde:

Limite de preferência $\left(p_{j}\right): a P_{j} b \leftrightarrow g_{j}(a)-g_{j}(b)>p_{j}$

Limite de indiferença $\left(q_{j}\right)$ : al $b \leftrightarrow-q_{j}<\left|g_{j}(a)-g_{j}(b)\right|<q_{j}$ Situação de preferência fraca: $a Q b \leftrightarrow q_{j}<\left|g_{j}(a)-g_{j}(b)\right|<p_{j}$ $g($.$) ganho no critério$

No cenário S1 (uso do algoritmo S1), as alternativas só contam como pontos (têm sua atratividade pontuada) para situações em que ocorre $a \mathrm{P}_{j} b$. A alternativa $a$ é comparada com todas as demais alternativas. Por exemplo, comparando a alternativa $a$ com a alternativa $b$, verifica-se os critérios nos quais ocorre $a \mathrm{P} b$, levando-se em consideração os limiares de preferência e de indiferença e a discordância. Verificada se satisfaz a condição imposta, tem-se que a domina $b$, posteriormente somam-se os pesos dos critérios nos quais a condição foi atendida. Para uma alternativa $c$, repete-se o mesmo procedimento descrito anteriormente. A pontuação (ou atratividade) final da alternativa a será a soma desses valores obtidos (GOMES et al., 2008).

Para o cenário S2, as alternativas contam como pontos para situações em que $a \mathrm{P}_{j} b$ e $a \mathrm{Q}_{j} b$. Já no cenário $\mathrm{S} 3$, as alternativas contam como pontos para situações em que $a \mathrm{P} b, a \mathrm{Q} b$ e al $b$. Nota-se que os dois últimos cenários ( $\mathrm{S} 2$ e S3) são menos rigorosas que o primeiro (S1), de forma que uma diferença menor permite classificar uma alternativa como melhor que outra (GOMES; GOMES; RANGEL, 2009).

A adoção dos algoritmos S1 e S2 do THOR não possibilitou obter do ranking. No entanto, ao se usar o S3 do THOR foi obtida a seguinte ordenação:

10 lugar: Bandeirado híbrido;

20 lugar: Crédito bandeirado;

$3^{\circ}$ lugar: Private Label.
Esses resultados foram obtidos considerando-se a situação de verdadeiros-critérios, na qual faz-se $p_{j=} q_{j=} 0$. Observa-se que o algoritmo S3 é menos rigoroso, permitindo uma ordenação, enquanto S1 e S2 não permitiram. 0 contraste entre os resultados apresentados pelo algoritmo S3 em relação àqueles apresentados pelos algoritmos S1 e S2 torna-se relevante, uma vez que ao se considerar apenas os do S3 poder-se-ia imaginar uma concordância plena com a afirmação de que a alternativa BH predomina sobre as demais. Por outro lado, o uso apenas dos algoritmos S1 e S2 não indicaria ao decisor uma alternativa a ser escolhida.

Foi efetuada uma análise adicional quanto à sensibilidade (no caso, estudos dos critérios que efetivamente contribuíam para a ordenação das alternativas) dos resultados ao conjunto de critérios utilizados. Essa análise fez uso da teoria dos conjuntos aproximativos (TCA) para eliminar critérios redundantes.

A TCA apoia-se na habilidade de classificar objetos. Nesse caso, um objeto pode ser algo real ou abstrato. Assim, dado um conjunto finito $U \neq$ $\emptyset$ de objetos (o universo), um subconjunto $\mathrm{X} \subseteq \mathrm{U}$ é referenciado como um conceito ou categoria em $\mathrm{U}$, podendo ser qualquer família de conceitos em $\mathrm{U}$ denominada conhecimento abstrato ou, de forma abreviada, conhecimento sobre U. Nesse ponto, relações de equivalência e classificações têm o mesmo significado, indistintamente. A relação de equivalência é conhecida como relação de indiscernibilidade e classes de equivalência são denominadas conjuntos elementares. Assim, se R é uma relação de equivalência sobre $\mathrm{U}$, então $\mathrm{U} / \mathrm{R}$ significa a família de todas as classes de equivalência de $R$. Se $P \subseteq R$ e $P \neq$ $\emptyset$, então $\cap P$ (interseção de todas as relações de equivalência pertencentes a P) é também uma relação de equivalência, indicada por IND(P), e é conhecida como relação de indiscernibilidade sobre P. Assim, $\mathrm{U} / \mathrm{IND}(\mathrm{P})$ significa a família de todas as classes de equivalência da relação de equivalência $\operatorname{IND}(\mathrm{P})$ e representa o conhecimento associado com a família de relações de equivalência de $\mathrm{P}$. De acordo com a TCA, um conjunto de conceitos elementares pode originar um conceito preciso (crisp ou precise), ou aproximativo, ou impreciso (rough ou imprecise). Assim, os conceitos aproximativos não podem ser expressos em termos de conceitos elementares, mas expressos com a utilização de aproximações inferior (lower) e superior (upper) de um conceito. A aproximação inferior de um conceito é a união de todos os conceitos elementares que estão inclusos naquele conceito; enquanto que a aproximação superior é a união de todos os conceitos elementares que têm alguma interseção (não vazia) com o conceito em questão. A diferença entre essas aproximações 
é conhecida como região de fronteira (boundary region). Entende-se o sistema de informação como uma tupla $S=(U, Q, V, f)$, onde $U$ é um conjunto finito de objetos, $Q$ é um conjunto finito de atributos, $V=\cup q \in Q V q$, onde $V q$ é o domínio do atributo $q$ e $f: U \chi Q \rightarrow V$ é uma função total tal que $\mathrm{f}(\mathrm{x}, q) \in$ $V q$ para cada $q \in Q, \mathrm{x} \in U$, conhecida como função de informação. Dado um sistema de informação $S=(U, Q, V, f), P \subseteq Q$ e x,y $\in U$, é dito que x e y são indiscerniveis pelo conjunto de atributos $P$ em $S$, se $\mathrm{f}(\mathrm{x}, q)=\mathrm{f}(\mathrm{y}, q)$ para todo $q \in P$. Portanto, todo $P \subseteq$ $Q$ gera uma relação binária em $U$, conhecida como relação de indiscernibilidade, denotada por $\operatorname{IND}(P)$. Dado que $P \subseteq Q$ e $Y \subseteq U$, a aproximação inferior ( $P Y)$ e a aproximação superior $(P Y)$ são definidas como $P Y=\cup\{\mathrm{X} \in \mathrm{U} / \mathrm{P}: \mathrm{X} \subseteq \mathrm{Y}\}$ e $P Y=\cup\{\mathrm{X} \in \mathrm{U} / \mathrm{P}: \mathrm{X} \cap$ $Y \neq \emptyset\}$. Assim, $Y$ é um conjunto aproximativo (rough) com relação a $P$ se e somente se $P Y \neq P Y$. A região de fronteira (borderline region) de um conjunto $Y$ é definida como $\mathrm{BnP}(\mathrm{Y})=P Y-P Y$. Para todo conjunto $Y \subseteq U$, pode-se associar a precisão (accuracy) de aproximação do conjunto $Y$ por $P$, em $S$ (Pawlak; Slowinski, 1994): $\alpha \mathrm{P}(Y)=\operatorname{card}(P Y) / \operatorname{card}(P Y)$. Para melhor detalhamento sobre a TCA consulte Gomes e Gomes (2012) e Couto e Gomes (2010)

Foram eliminados os critérios: Custo por transação, Necessidade de investimentos futuros, Fidelização do varejista, Número de locais que atende, Usabilidade do cliente, Facilidade de difusão, Aplicações adicionais, Risco cliente e Risco varejista.

A TCA utilizada nesse caso, no conjunto dos critérios, fez uma aproximação dita superior, onde estão todos os critérios, e a aproximação dita inferior, que inclui os critérios relevantes, no caso, a retirada desses altera a ordenação das alternativas, inicialmente sugerida com todos os critérios.

Com a eliminação desses critérios obtêm-se os resultados apresentados na Tabela 1. 0 uso da TCA permitiu avaliar e garantir que não houve perda de informação na ordenação.

0 Thor permitiu a ordenação das alternativas no algoritmo S3. Entretanto, a diferença da pontuação de cada alternativa foi muito próxima - a pontuação traduz a atratividade da alternativa para o decisor, isso demonstrou, pelo uso do método, que a diferença de atratividade era pequena.

\subsubsection{Aplicação do ELECTRE 1}

Por se tratar de um problema de escolha $(\mathrm{P} \alpha)$, utilizou-se o método ELECTRE 1 como tentativa para obter-se o conjunto unitário de alternativas não dominadas - o qual conteria a alternativa a ser escolhida. Para isso foram calculadas as relações de concordância e discordância.

0 método ELECTRE 1 (Roy, 1968) é o primeiro de uma família de métodos que usam o conceito de superação e foi concebido para resolver questões da problemática $(\mathrm{P} \alpha)$, isto é, tentar esclarecer a decisão por meio da escolha de um subconjunto, tão restrito quanto possível, contendo as ações que foram consideradas as melhores. Para atingir esse objetivo, o ELECTRE 1 explora relações de concordância e de discordância, construindo relações de sobreclassificação ou subordinação, de tal forma que uma alternativa sobreclassifica outra se há uma concordância superior a um nível de concordância mínima ( $\mathrm{C}^{*}$ ) e uma discordância inferior a um nível de discordância máxima ( $\left.\mathrm{d}^{*}\right)$. A partir das relações de sobreclassificação, obtêm-se uma partição do conjunto de alternativas em dois subconjuntos: subconjunto $K$ (ou núcleo) de alternativas não dominadas, e subconjunto D, composto por alternativas dominadas ou sobreclassificadas.

Roy (1968) estabelece que essa partição tenha as seguintes propriedades:

- Uma alternativa pertencente ao subconjunto $\mathrm{K}$ não é sobreclassificada ou dominada por nenhuma alternativa também pertencente a $\mathrm{K}$;

- Toda alternativa em D é sobreclassificada ou dominada por pelo menos uma alternativa em K.

Por conseguinte pode-se afirmar que o subconjunto K sobreclassifica ou domina o subconjunto D. É importante destacar que essa é uma relação entre os subconjuntos, não sendo aplicável a alternativas individualmente. Ou seja: não implica que toda alternativa em D seja dominada ou sobreclassificada por toda alternativa em K. Essa observação se faz importante, pois é usual ter-se a interpretação de que toda alternativa em $\mathrm{D}$ é dominada por toda alternativa em K.

A Figura 7 apresenta os valores das matrizes de concordância e discordância, utilizando todos os critérios, calculadas em acordo com Roy (1968) e o

Tabela 1. Ordenação das alternativas com a redução do conjunto de critérios.

\begin{tabular}{cccccc}
\hline Algoritmos & & \multicolumn{5}{c}{ Posição no ranking } \\
\hline S1 & Private label & $=$ & Crédito bandeirado & $=$ & Bandeirado híbrido \\
S2 & Private label & $=$ & Crédito bandeirado & $=$ & Bandeirado híbrido \\
S3 & Bandeirado híbrido & $>$ & Crédito bandeirado & $>$ & Private label \\
\hline
\end{tabular}


apoio do sistema computacional Multicriteria Lab, desenvolvido por Galvão e Costa (2005).

Observa-se, pela análise dos resultados oriundos da aplicação do ELECTRE 1, que não há uma alternativa que tenha uma sobreclassificação significativa sobre as demais. Portanto, não há alternativas dominadas e o núcleo é composto por todas as alternativas, o que não possibilita a eliminação de alguma alternativa, objetivando a escolha. Esse resultado indica uma incomparabilidade entre as alternativas, devido a não existência de uma alternativa dominante, o que se traduz, para o decisor, na não indicação de uma alternativa para a escolha. 0 resultado da não indicação de uma alternativa dominante é, para o decisor, semelhante ao obtido pela aplicação dos algoritmos S2 e S3 do Thor aos dados coletados.

Observa-se que ao se relaxar o nível de exigência quanto à concordância e à discordância (concordância mínima de 0,67 e discordância máxima de 0,5), é possível obter um núcleo composto por uma única alternativa (BH), que sobreclassifica as demais (CB e PL). Como se trata de um problema de escolha, a alternativa BH seria a indicada para a seleção pelo método ELECTRE 1, desde que se aceitassem os valores citados para os planos de corte.

\subsubsection{Aplicação do ELECTRE 11}

0 método ELECTRE 11 (Roy; Bertier, 1971) pode ser considerado uma extensão do método ELECTRE 1 para problemas de ordenação ou ranking. Baseado nas relações de concordância e discordância do ELECTRE 1 e relaxando os graus de exigência para sobreclassificação, esse método constrói dois grafos: um representando uma sobreclassificação forte e outro, uma sobreclassificação fraca. Da aplicação do ELECTRE 11 resulta um ranking das alternativas, sendo indicado para a problemática de ordenação.
A ideia com o uso do ELECTRE 11 é escolher as alternativas preferidas na maioria dos critérios que não ultrapassem um determinado nível de desconforto ou descontentamento aceito pelo decisor.

0 procedimento de ordenação do método ELECTRE 11 constitui-se de dois estágios distintos de preordenação. No primeiro estágio define-se uma preordenação progressiva e, no segundo, a regressiva. As duas preordenações obtidas, possivelmente, são diferentes, porém próximas. No caso de preordenações diferentes, as mesmas são combinadas em uma ordenação final através da posição média entre elas.

Os resultados da modelagem indicam que a ordenação das alternativas só foi possível ao se relaxarem as exigências de concordância e discordância. A Tabela 2 apresenta a ordenação obtida com parâmetros de corte também ilustrados nesta tabela.

Em particular, destaca-se que o método ELECTRE 11, reportado por Brans, Mareschal e Vincke (1984), tem em seu algoritmo um relaxamento dos níveis de exigência quanto a concordância e discordância, relaxamento esse traduzido na construção de dois grados (um forte e um outro fraco). Esse relaxamento torna o ELECTRE 11 "mais benevolente" na definição de relações de predominância e, consequentemente, "mais propício" a indicar uma alternativa para escolha do que o ELECTRE 1.

Observa-se que o fato de utilizarem-se os dois métodos para análise do problema foi pertinente, visto que a ordenação pelo uso do ELECTRE 11, mesmo tendo

Tabela 2. Ordenação pelo ELECTRE 11.

\begin{tabular}{ccc}
\hline \multicolumn{2}{c}{ Parâmetros de corte } & \\
\cline { 1 - 2 } Concordância & Discordância & \\
\hline$C_{1}=0,7$ & $\mathrm{~d}_{1}=0,8$ & $1^{\circ} \rightarrow \mathrm{BH}$ \\
$\mathrm{C}_{2}=0,6$ & $\mathrm{~d}_{2}=0,2$ & $2^{\circ} \rightarrow \mathrm{PL} ; \mathrm{CB}$ \\
$\mathrm{C}_{3}=0,5$ & & \\
\hline
\end{tabular}

Multicriteria Lab - [F:la_BaselaEssenciais Multicriteria lab_exelMulticriteria lab_exelArtigo Cartão de crédito.amd] Arquivos Entradade Dados Electre I Electre II Electre II Electre Tri Promethée MP LexicoGráfico Borda Relatórios... Opçoes Ajuda

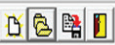

\begin{tabular}{l}
\hline T. Matriz de Concordância \\
\begin{tabular}{|l|l|l|l|l||}
\hline All $\rightarrow$ All & BH & PL & CB & \\
\hline BH & 1 & 0,77 & 0,67 & \\
\hline PL & 0,28 & 1 & 0,39 & \\
\hline CB & 0,54 & 0,61 & 1 & \\
\hline & & & & \\
\hline
\end{tabular}
\end{tabular}

\begin{tabular}{|c|c|c|c|c|}
\hline \multicolumn{4}{|c|}{ Matriz de Discordância } & $-|\square| x \mid$ \\
\hline All $>$ Alt & $B H$ & PL & $C B$ & \\
\hline $\mathrm{BH}$ & 0 & 0,5 & 0,5 & \\
\hline $\mathrm{PL}$ & 1 & 0 & 1 & \\
\hline$C B$ & 0,75 & 1 & 0 & \\
\hline
\end{tabular}

Figura 7. Tela do Multicriteria Lab com as matrizes de concordância e discordância. 
um relaxamento interno, não destaca para o decisor esse relaxamento, podendo criar a falsa impressão de que existe uma concordância plena quanto a que uma alternativa é de fato superior às demais.

\subsubsection{Aplicação do PROMETHÉE 11}

Os cálculos do PROMETHÉE 11 resultam em uma pré-ordem completa das alternativas e, conforme reportado por Brans, Mareschal e Vincke (1984) há seis diferentes funcionais para expressar a relação de preferência (P) no PROMETHÉE 11. A Tabela 3, construída a partir de Brans, Mareschal e Vincke (1984), Almeida e Costa (2002) e De Carvalho et al. (2011), expressa esses diferentes funcionais. Observa-se que os termos que aparecem na primeira coluna dessa Tabela 3 estão de acordo com a classificação de critérios reportada em Vincke (1989), Freitas (1997) e Rogers, Bruen e Maystre (2000) - à exceção do termo Gaussiano, inserido em função das definições apresentadas em Brans, Mareschal e Vincke (1984).

Almeida e Costa (2002) observam que a função $P_{j}$ pode assumir valores entre 0 e 1 e que esses aumentam na direção de 1 se a diferença de desempenho ou a vantagem de uma alternativa a em relação a outra b aumenta e é igual a zero se o desempenho de a é inferior ou igual ao de $b$.

Com base nas funções de preferência $\mathrm{P}$, o método PROMETHÉE 11 ordena as alternativas com base no fluxo líquido de dominância $(\phi(a))$, calculado pela seguinte expressão:

$\phi(a)=\phi^{+}(\mathrm{a})-\phi^{-}(\mathrm{a})$

onde:

- $\phi$ (a) é o fluxo líquido de dominância associado à alternativa $a$;
- $\phi^{+}($a) é o fluxo positivo de dominância associado à alternativa $a$; esse fluxo busca medir quanto uma alternativa a domina as demais alternativas;

- $\phi^{-}$(a) é o fluxo negativo de dominância associado à alternativa $a$; este fluxo busca medir quanto uma alternativa $a$ é dominada pelas demais alternativas.

A obtenção dos valores de $\phi^{+}\left(\right.$a) e $\phi^{-}$(a) é função de relações de preferência entre as alternativas. $0 u$ seja:

$\phi^{+}(a)=\Sigma w_{j},\left(a_{j} b_{k}\right)$, com j= $1 \ldots$ n e k $=1 . . m$.

$\phi^{-}(\mathrm{a})=\Sigma \mathrm{w}_{\mathrm{j},} \mid\left(\mathrm{b}_{\mathrm{k}} \mathrm{P}_{\mathrm{j}} \mathrm{a}\right)$, com $\mathrm{j}=\mathrm{i} \ldots \mathrm{n}$ e $\mathrm{k}=1 . . \mathrm{m}$.

onde:

- n é o número de critérios;

- m é o número de alternativas;

- $\mathrm{aP}_{\mathrm{j}} \mathrm{b}_{\mathrm{k}}$ é a função de preferência de $a$ em relação a $b$, no critério j.

Este valor é igual ao valor de $\mathrm{P}(\mathrm{a}, \mathrm{b})$ no critério $\mathrm{j}$, definido conforme explicitado na Tabela 3; os cálculos do PROMETHÉE 11 resultam numa pré-ordem completa das alternativas, entretanto não admitem relação de incomparabilidade.

No caso do problema em tela, optou-se por utilizar a primeira função da Tabela 3, função degrau, para representar a função de preferência. A escolha dessa função se deve ao fato de a mesma adotar o critério verdadeiro, assim como os ELECTRE 1 e 11 , o que facilita a comparação entre os resultados. A Tabela 4 apresenta os resultados obtidos pela aplicação do PROMETHÉE 11 aos dados presentes na Figura 6. Seguindo os resultados desse método, observou-se que o Cartão bandeirado híbrido ficou em primeiro lugar, seguido pelo Cartão bandeirado ( $2^{\circ}$ lugar) e pelo cartão Private Label ( $3^{\circ}$ lugar).

Tabela 3. Funções de preferência no método PROMETHÉE.

\begin{tabular}{|c|c|c|c|}
\hline Tipo de critério & Formulação & & $\begin{array}{l}\text { Forma da } \\
\text { função }\end{array}$ \\
\hline Critério verdadeiro & $\begin{array}{l}g j(a)-g j(b)>0 \\
g j(a)-g j(b) \leq 0\end{array}$ & $\begin{array}{l}P_{j}(a, b)=1 \\
P_{j}(a, b)=0\end{array}$ & Degrau \\
\hline Quase critério & $\begin{array}{l}g j(a)-g j(b)>q_{j} \\
g j(a)-g j(b) \leq q_{j}\end{array}$ & $\begin{array}{l}P_{j}(a, b)=1 \\
P_{j}(a, b)=0\end{array}$ & $U$ \\
\hline Semicritério (com variação linear) & $\begin{array}{l}g j(a)-g j(b)>p_{j} \\
g j(a)-g j(b) \leq p_{j} \\
g j(a)-g j(b) \leq 0\end{array}$ & $\begin{array}{l}P_{j}(a, b)=1 \\
P_{j}(a, b)=[g j(a)-g j(b)] / p_{j} \\
P_{j}(a, b)=0\end{array}$ & $V$ \\
\hline Pseudocritério (com variação discreta) & $\begin{array}{l}|\operatorname{gj}(a)-g j(b)|>p_{j} \\
q<|\operatorname{gj}(a)-g j(b)| \leq p_{j} \\
|g j(a)-g j(b)| \leq q \\
|\operatorname{gi}(a)-\operatorname{qj}(b)|>p\end{array}$ & $\begin{array}{l}P_{j}(a, b)=1 \\
P_{j}(a, b)=1 / 2 \\
P_{j}(a, b)=0 \\
P(a, b)=1\end{array}$ & Degraus \\
\hline Pseudocritério (com variação linear) & $\begin{array}{l}|g j(a)-\operatorname{gj}(b)|>p_{j} \\
q<|\operatorname{gj}(a)-\operatorname{gj}(b)| \leq p_{j} \\
|\operatorname{gj}(a)-\operatorname{gj}(b)| \leq q_{j}\end{array}$ & $\begin{array}{l}P_{j}(a, b)=1 \\
P_{j}(a, b)=\left[/ g j(a)-g j(b) /-q_{j}\right] /\left(p_{j}-q_{j}\right) \\
P_{j}(a, b)=0\end{array}$ & Variação linear \\
\hline Gaussiano & $\begin{array}{l}g j(a)-g j(b)>0 \\
g j(a)-g j(b) \leq 0\end{array}$ & $\begin{array}{l}\text { A preferência aumenta segundo uma distribuição normal } \\
P_{i}(a, b)=O\end{array}$ & Gaussiana \\
\hline
\end{tabular}


Observa-se que o algoritmo do PROMETHÉE 11 adotado, baseado na função degrau de preferências, estabeleceu uma relação de ordem entre toda as três alternativas, sem empates ou incomparabilidades. Esse fato ocorre porque o algoritmo do PROMETHÉE é "mais benevolente" do que os do ELECTRE 1 e 11 , essa "benevolência" reside no fato de que para o PROMETHÉE 11 basta uma alternativa ter um fluxo líquido maior do que outra para ser ordenada em uma posição superior no ranking, ao passo que nos métodos ELECTRE é necessário que haja uma relação de sobreclassificação atendendo a planos de corte estabelecidos por níveis de concordância mínima e de discordância máxima.

\subsection{Comparação dos resultados e decisão adotada}

A Tabela 5 apresenta uma compilação dos resultados apresentados pelos métodos. 0 uso dos três métodos de ordenação (THOR S3, ELECTRE 11 E PROMETHÉE 11) e de um método de escolha (ELECTRE 1) convergiu para a indicação de que a alternativa de cartão de crédito a ser adotada pelo decisor deveria ser o cartão tipo Bandeirado híbrido.

Observa-se que o uso dos algoritmos THOR S1 e S2 gerou o empate entre a atratividade dos cartões considerados, quando analisados à luz desses algoritmos. 0 ELECTRE 1 com os níveis de exigência máximos (grau de concordância mínima $c^{*}$ igual a 1 e discordância máxima $d^{*}$ igual a 0) indicou incomparabilidades entre as alternativas. Esses resultados fornecidos pelo THOR S1 e S2 e pelo ELECTRE 1 indicaram que não há uma aceitação plena em que uma alternativa sobreclassifica as demais.

A sugestão do THOR S3 foi semelhante à sugestão do PROMETHÉE 11 e do ELECTRE 11,

Tabela 4. Ordenação pelo PROMETHÉE 11.

\begin{tabular}{lcccc} 
Alternativa & $\begin{array}{c}\text { Fluxo } \\
\text { positivo } \\
\left(\phi^{+}\right)\end{array}$ & $\begin{array}{c}\text { Fluxo } \\
\text { negativo } \\
\left(\phi^{-}\right)\end{array}$ & $\begin{array}{c}\text { Fluxo } \\
\text { líquido } \\
\left(\phi^{0}\right)\end{array}$ & Ordenação \\
\hline Híbrido (BH) & 1.610 & 1.040 & 570 & $1^{\circ}$ \\
Private (PL) & 755 & 1.545 & -790 & $3^{\circ}$ \\
Bandeirado (CB) & 1.405 & 1.185 & 220 & $2^{\circ}$ \\
\hline
\end{tabular}

Tabela 5. Compilação das sugestões dos métodos.

\begin{tabular}{llllll}
\hline THOR S1 & $\mathrm{BH}$ & $=$ & $\mathrm{CB}$ & $=$ & $\mathrm{PL}$ \\
THOR S2 & $\mathrm{BH}$ & $=$ & $\mathrm{CB}$ & $=$ & $\mathrm{PL}$ \\
THOR S3 & $\mathrm{BH}$ & $>$ & $\mathrm{CB}$ & $>$ & $\mathrm{PL}$ \\
ELECTRE 1 & $\mathrm{BH}$ & $\mathrm{R}$ & $\mathrm{CB}$ & $\mathrm{R}$ & $\mathrm{PL}$ \\
$\mathrm{C}^{*}=1,0 ; \mathrm{d}^{*}=0,0$ & $\mathrm{BH}$ & $\mathrm{R}$ & $\mathrm{PL}$ & $\mathrm{R}$ & $\mathrm{CB}$ \\
ELECTRE $1^{*}$ & $\mathrm{BH}$ & $>$ & $\mathrm{CB}$ & $\mathrm{R}$ & $\mathrm{PL}$ \\
$\mathrm{C}^{*}=0,67 ; \mathrm{d}^{*}=0,5$ & $\mathrm{BH}$ & $=$ & $\mathrm{PL}$ & $\mathrm{R}$ & $\mathrm{CB}$ \\
ELECTRE 11 & $\mathrm{BH}$ & $>$ & $\mathrm{CB}$ & $\mathrm{R}$ & $\mathrm{PL}$ \\
PROMETHÉE 11 & $\mathrm{BH}$ & $>$ & $\mathrm{PL}$ & $\mathrm{R}$ & $\mathrm{CB}$ \\
\end{tabular}

indicando ordenação entre as alternativas, tendo indicado a alternativa $\mathrm{BH}$ em primeiro lugar. Essa alternativa também foi indicada com não dominada após relaxarem-se os parâmetros de exigência do ELECTRE 1 quanto aos níveis de concordância mínima e discordância máxima.

\section{Conclusão}

Com base nos resultados obtidos pela aplicação dos diferentes métodos multicritério ao conjunto de dados e também pelas análises de sensibilidades efetuadas, o decisor pôde efetivar a sua decisão com maior conhecimento sobre o problema, adquirido através das modelagens efetuadas.

Os resultados obtidos indicam que não há uma concordância plena de que uma alternativa seja dominante em relação às demais. Esse fato ficou ressaltado pela aplicação dos algoritmos do THOR S1 e S2 e, também, pelo teste realizado com o ELECTRE 1 em nível máximo de exigência $\left(c^{*}=1,0 ; d^{*}=0,0\right)$ que indicaram, respectivamente, empate entre as alternativas (THOR S1 e S2) ou incomparabilidades entre elas (ELECTRE 1 com exigência máxima).

Devido a necessidade de o decisor estabelecer um juízo, foram efetuados relaxamentos no grau de exigência do ELECTRE 1, adotando-se $c^{*}=0,67$ e $^{*}=0,5$. Essa ação indicou as alternativas CB e PL como dominadas pela alternativa BH. Objetivando verificar a robustez dessa indicação, foram utilizados os algoritmos de ordenação de THOR S3, ELECTRE 11 e PROMETHÉE 11 para obter-se uma ordenação das alternativas. As ordenações obtidas pelos três algoritmos convergiram ao indicar a alternativa $\mathrm{BH}$ em primeiro lugar no ranking.

Comparando-se os resultados indicados pelos diferentes algoritmos conclui-se que eles se complementam: utilizando-se apenas os algoritmos de ordenação obter-se-ia o ranking, porém poder-se-ia ter a falsa impressão de que haveria uma dominância plena da alternativa $\mathrm{BH}$ sobre as demais; por outro lado, o uso dos algoritmos S1, S2 e ELECTRE 1 (em seu nível máximo de exigência) não conseguiu indicar ao decisor uma alternativa que dominasse as demais - 0 que não satisfez ao decisor que precisava, de fato, fazer uma escolha.

Tomando-se em conta o conjunto de resultados apresentados por esses diferentes métodos, o decisor optou pela alternativa de cartão do tipo Bandeirado híbrido, convicto de que essa opção era ligeiramente mais indicada que as demais no atendimento das necessidades da organização.

Este estudo (multimétodos) agregou maior segurança à ação do decisor - pelo maior conhecimento por ele adquirido -, considerando importante o uso de vários métodos para: 
- Dar maior robustez à decisão, visto que considerou as indicações apresentadas por diferentes métodos multicritério, tendo sido observada uma razoável convergência de resultados;

- Melhorar o entendimento e aprendizado da problemática abordada;

- Uma melhor compreensão das relações de preferência e dominância entre as alternativas.

Como sugestões para trabalhos futuros, pode-se aplicar esta abordagem multimétodos em outros problemas e incluir métodos da Escola Americana.

\section{Referências}

AKSU, M.; PEKTAŞ, G. Ö. E.; ESEOĞLU, M. Fashion Phenomenon in Postmodern Marketing Applications and Effects on the Marketing Components. Procedia - Social and Behavioral Sciences, v. 24, p. 325-339, 2011. http:// dx.doi.org/10.1016/j.sbspro.2011.09.126

ALBERTIN, R. M. D. M.; ALBERTIN, A. L. Tecnologia da Informação e Desempenho Empresarial. Rio de Janeiro: Atlas, 2009.

ALENCAR, L. H.; COSTA, A. P. C. S.; GOMES, C. F. S. Gerenciamento de projeto na construção civil utilizando o apoio multicriterio a decisão. Revista de la Escuela de Perfeccionamiento en Investigacion Operativa, v. 26, p. 163-186, 2005.

ALMEIDA, A. T. D.; COSTA, A. P. C. S. Modelo de decisão multicritério para priorização de sistemas de informação com base no método PROMETHEE. Gestão \& Produção, v. 9 , n. 2, p. 201-214, 2002. http://dx.doi.org/10.1590/ S0104-530X2002000200007

ALVES, A. A.; MENEZES, 0. M. S. Cartão de crédito private label. Rio de Janeiiro: Novatec, 2007.

ANTUNES, H. A. et al. Algumas reflexões sobre uma base de métodos de programação linear multicritério. Investigação Operacional, v. 9, n. 2, p. 19-35, 1989.

ASSOCIAÇÃO BRASILEIRA DAS EMPRESAS DE CARTÕES DE CRÉDITO E SERVIÇOS - ABECS. Evolução dos Indicadores do mercado de cartões. ABECS, 2012. Disponível em: $<$ http://www.abecs.org.br/mercado_cartoes.asp/>.

AYDIN, S. et al. The measurement of switching costs as a perception of customers in the Turkish credit card market. Journal of Electrical and Electronics Engineering, v. 9, n. 2, p. 1015-1028, 2009.

BELTON, V.; STEWART, T. J. Multiple criteria decision analysis: an integrated approach. Massachusetts: Kluwer Academic Publishers, 2004.

BOUYSSOU, D. Some remarks on the notion of compensation in MCDM. European Journal of Operational Research, v. 26, n. 1 , p. 150-160, 1986. http://dx.doi.org/10.1016/03772217(86)90167-0

BRANS, J. P.; MARESCHAL, B. The PROMCALC \& GAIA decision support system for multicriteria decision aid. Decision Support Systems, v. 12, n. 4-5, p. 297-310, 1994. http://dx.doi.org/10.1016/0167-9236(94)90048-5

BRANS, J. P.; MARESCHAL, B.; VINCKE, P. Promethee: A New Family Of Outranking Methods In Multicriteria Analysis. In: INTERNATIONAL CONFERENCE OF OPERATIONAL RESEARCH, 10., 1984, Washington. Proceedings... Washington: North-Holland, 1984.

CARDOSO, R. et al. Uso de SAD no Apoio à Decisão na Destinação de Resíduos Plásticos e Gestão De Materiais.
Pesquisa Operacional, v. 29, n. 1, p. 67-95, 2009. http:// dx.doi.org/10.1590/S0101-74382009000100004

COELHO, L. S.; RAITTZ, R. T.; TREZUB, M. F. Control ${ }^{\circledR}$ : sistema inteligente inovador para detecção de fraudes em operações de comércio eletrônico. Gestão \& Produção, v. 13, n. 1, 2006. http://dx.doi.org/10.1590/S0104$530 \times 2006000100012$

COUTO, A. B. G.; GOMES, L. F. A. M. A tomada de decisão em recursos humanos com dados replicados e inconsistentes: uma aplicação da teoria dos conjuntos aproximativos Pesquisa Operacional, v. 30, n. 3, p. 657686, set./dez. 2010. http://dx.doi.org/10.1590/S010174382010000300009

COSTA, H. G. et al. ELECTRE TRI applied to costumers satisfaction evaluation. Produção, v. 17, n. 2, p. 230-245, 2007. http://dx.doi.org/S0103-65132007000200002

CRESWELL, J. W. Educational research: planning, conducting, and evaluating quantitative and qualitative research. New York: Pearson Education, 2011.

DE CARVALHO, J. R. M. et al. Metodologia para Avaliar a Sustentabilidade Ambiental de Municípios Utilizando Análise Multicritério. REUNIR - Revista de Administração, Contabilidade e Sustentabilidade, v. 1, n. 1, p. 18-34, 2011.

DE OLIVEIRA, T. M. D.; IKEDA, A. A.; SANTOS, R. C. Compra compulsiva e a influência do cartão de crédito. $R A E$, v. 44 , n. 3, p. 89-99, 2004.

DESCARTES, R. Discours de la méthode. Paris: Victor Cousin, 1637.

EDWARDS, W. How To Use Multiattribute Utility Measurement For Social Decisionmaking. IEEE Transactions on Systems, Man and Cybernetics, v. SMC-7, n. 5, p. 326-340, 1977. http://dx.doi.org/10.1109/TSMC.1977.4309720

FISHBURN, P. C. Stationary value mechanisms and expected utility theory. Journal of Mathematical Psychology, v. 3 , n. 2, p. 434-457, 1966. http://dx.doi.org/10.1016/00222496(66)90023-X

FISHBURN, P. C. Additive representations of real functions on product sets. Journal of Combinatorial Theory, v. 4, n. 4, p. 397-402, 1968. http://dx.doi.org/10.1016/S00219800(68)80065-1

FISHBURN, P. C. Utility theory with inexact preferences and degrees of preference. Synthese, v. 21, n. 2, p. 204-221, 1970. http://dx.doi.org/10.1007/bf00413546

FREITAS, A. L. P. Avaliação e classificação da qualidade em serviços: uma abordagem multicritério. 1997. Dissertação (Mestrado em Engenharia de Produção)-Universidade Estadual do Norte Fluminense, Campos dos Goytacazes, 1997.

GALVÃO, R.; COSTA, H. G. Multicriteria Lab: a computater program for supporting multi-methods MCDA models. Niterói, 2005.

GOMES, C. F. S. THOR - um algoritmo híbrido de apoio multicritério à decisão para processos decisórios com alternativas discretas. 1999. Tese (Doutorado em Engernharia de Produção)-Universidade Federal do Rio de Janeiro, Rio de Janeiro, 1999.

GOMES, C. F. S. Using MCDA methods THOR in an application for outranking the ballast water management options. Pesquisa Operacional, v. 25, n. 1, p. 11-28, 2005. http:// dx.doi.org/10.1590/S0101-74382005000100002

GOMES, C. F. S. et al. Identificação de Hub Ports na Costa Brasileira Comparação Entre a Análise Conjunta e o SadThor. Revista de la Escuela de Perfeccionamiento en Investigación Operativa, v. 17, p. 143-159, 2009. 
GOMES, C. F. S.; COSTA, H. G. Aplicação de Métodos Multicritério ao Problema de Escolha de Modelos de Pagamentos Eletrônicos por Cartão de Crédito. In: SIMPÓSIO BRASILEIRO DE PESQUISA OPERACIONAL (SBP0), 43., 2011, Ubatuba. Anais... Ubatuba: Sociedade Brasileira de Pesquisa Operacional, 2011.

GOMES, C. F. S. et al. Multicriteria decision making applied to waste recycling in Brazil. Omega, v. 36, n. 3, p. 395-404, 2008. http://dx.doi.org/10.1016/j.omega.2006.07.009

GOMES, L. F. A. M. Comparing two methods for multicriteria ranking of urban transportation system alternatives. Miami: Publ by lnst of Transportation, 1989.

GOMES, L. F. A. M.; GOMES, C. F. S. Tomada de Decisão Gerencial: o Enfoque Multicritério. Rio de Janeiro: Atlas, 2012.

GOMES, L. F. A. M.; GOMES, C. F. S.; RANGEL, L. A. D. A comparative Decision Analysis with THOR and TODIM: rental evaluation in Volta Redonda. Revista Tecnologia (UNIFOR), v. 30, p. 7-11, 2009.

GONZAGA, F. Cartões de crédito com RFID. 2010. Disponível em: <http://fe.eti.br/category/meios-de-pagamentos/>. Acesso em: 5 mar. 2010

GOUMAS, M.; LYGEROU, V. Extension of the PROMETHEE method for decision making in fuzzy environment: Ranking of alternative energy exploitation projects. European Journal of Operational Research, v. 123, n. 3 , p. 606-613, 2000. http://dx.doi.org/10.1016/s03772217(99)00093-4

GUIMARÃES NETO, C. A. Critérios de Avaliação e NB502-89. In: INSTITUTO DE ENGENHARIA LEGAL (Ed.). Introdução à Engenharia de Avaliações e Perícias Judiciais. São Paulo: Instituto de Engenharia Legal, 1992. p. 45-60.

HU, Y. C.; CHEN, H. C. Integrating multicriteria PROMETHEE 11 method into a single-layer perceptron for two-class pattern classification. Neural Computing and Applications, v. 20 , n. 8, p. 1263-1271, 2011. http://dx.doi.org/10.1007/ s00521-010-0424-2

KEENEY, R. L.; RAIFFA, H. Decisions with Multiple Objectives: preferences and value tradeoffs. New York: John Willey \& Sons, 1976.

MELO, L. D. B. L. Cartão de crédito: revisão de portfólio de produtos. Caso: Losango Promoções de Vendas. Rio de Janeiro: lbmec RJ, 2006.

MOUSSEAU, V.; SLOWINSKI, R.; ZIELNIEWICZ, P. ELECTRE TRI 2.0a. methodological guide and user's manual. Paris: Université de Paris-Dauphine, 1999. Document du LAMSADE.
PESSOA, M. Laudos técnicos, conceitos básicos e definições. In: INSTITUTO DE ENGENHARIA LEGAL (Ed.). Introdução à Engenharia de Avaliações e Perícias Judiciais. São Paulo: Instituto de Engenharia Legal, 1992. p. 1-26.

ROGERS, M.; BRUEN, M.; MAYSTRE, L. ELECTRE and decision support: methods and applications in nngineering and infrastructure investment. New York: Kluwer Academic Publishers, 2000.

ROY, B. Classement et choix en presence de points de vue multiples (la methode ELECTRE). Lausanne: Presses Polytechiniques et Universitaires Romandes, 1968.

ROY, B. ELECTRE 111: Un alghoritme de methode de classements fonde sur une representatio floue des preferences em presence de criteres multiples. Cahieres de CERO, v. 20, n. 1, p. 3-24. 1978.

ROY, B.; BERTIER, P. M. La methode ELECTRE II: Une methode de classement en presence de criteres multiples. Paris: SEMA (Metra International), 1971. p. 45.

ROY, B.; BOYSSOU, D. Aid Multicritère à la decision. Paris: Ed Economica, 1993.

ROY, B.; SKALKA, J. M. ELECTRE IS: Aspécts methodologiques et guide d'utilization. Paris: Université de Paris-Dauphine, 1984.

SAAB, W. G. L.; TAVARES, M. M. Evolução recente dos meios de pagamento e da cesta de consumo no varejo de alimentos no Brasil. BNDES Setorial, n. 15, p. 97-111, 2002.

SAATY, T. L. The analytic hierarchy process: planning, priority setting, resource allocation. New York: McGraw-Hill International Book Co., 1980

SAATY, T. L. Decision making for leaders - the Analytic Hierarchy Process for decisions in a complex world. Pittsburgh: RWS Publications, 1999.

SAATY, T. L.; PENIWATI, K. Group decision making: drawing out and reconciling differences. Pittsburgh: RWS Publications, 2008.

SAATY, T. L.; VARGAS, L. G. Decision making with the analytic network process: economic, political, social and technological applications with benefits, opportunities, costs and risks. New York: Springer, 2006. (International series in operations research \& management science).

VINCKE, P. L'aide Multicritère à la Decision. Bruxeles: Editions de l'Université de Bruxelles - Editions Ellipses, 1989.

WORTHINGTON, S.; RUSSELL-BENNETT, R.; HÄRTEL, C. A tridimensional approach for auditing brand loyalty. Journal of Brand Management, v. 17, n. 4, p. 243-253, 2010. http://dx.doi.org/10.1057/bm.2009.24

\title{
Application of multicriteria methods to the problem of choice models of electronic payment by credit card
}

\begin{abstract}
Currently, there is an increase in the usage of electronic payment devices, reflecting a market trend. This paper presents a study that compares the results of applying different multicriteria decision aid (MCDA) methods to evaluate the three types of electronic payment technologies that are most commonly used in Brazil; the results are used to create a decision maker for choosing one method from among these three alternatives. To achieve this objective, this paper uses a set of methods: THOR (S1, S2 and S3), ELECTRE (1 and 11) and PROMETHÉE 11. The results indicate that there is a slight prevalence of alternative technology. The adoption of multi-methods in this approach provided a sensitivity analysis that justified the decision maker's choice, revealing the slight advantage of one technology. However, this advantage was minimal, which could justify the adoption of all three technologies for electronic payment devices.
\end{abstract}

Keywords

Technology. Multicriteria. Electronic payments. 